\title{
An itchy genital eruption
}

\section{Anissa Zaouak, Oumayma Magdoud, Houda Hammami, Samy Fenniche}

\author{
Dermatology Department, Habib Thameur Hospital, Tunis, Tunisia
}

Corresponding author: Dr. Anissa Zaouak, E-mail: anissa_zaouak@yahoo.fr

Sir,

A 26-year-old male without a significant medical history was referred to our dermatology department for evaluation of an itchy eruption on the pubic area persistent for ten days prior. A skin examination revealed multiple brownish macules $1-2 \mathrm{~mm}$ in size in the hair of the thighs and genitalia and overlying particles attached near the base of the pubic hairs (Fig. 1). Dermoscopy showed moving pubic lice (Fig. 2) and nits firmly attached to the pubic hair. There was no inguinal lymphadenopathy. Hence, the diagnosis of pediculosis pubis was confirmed. The patient was treated with a $25 \%$ benzyl benzoate lotion one week apart and advised to shave the pubic hairs. After a week of treatment, there was a resolution of the genital pruritus and no lice were seen on a followup. A screening for sexually transmitted disease was performed and was negative.

Pediculosis pubis is an infectious disease caused by the louse Pthirus pubis. Its diagnosis is based mainly on clinical findings, and its main clinical diagnostic feature is severe itching in the pubic area $[1,2]$. Infested patients may also develop asymptomatic bluish-gray macules (maculae ceruleae) secondary to hemosiderin deposition from louse bites [3].

Dermoscopy allows for the visualization of nits and moving lice on the pubic hairs, yielding definitive evidence of active infestation [2].

Dermoscopy appears to be a quick, accurate, reliable, and adjuvant tool in confirming the diagnosis by exposing lice with crab-like claws and body shapes firmly attached to the pubic hairs [4]. Apart from the pubic area, other body areas may be involved, such as the scalp, eyelashes, eyebrows, chest, axillary regions, thighs, and buttocks [1]. Pediculosis pubis is considered

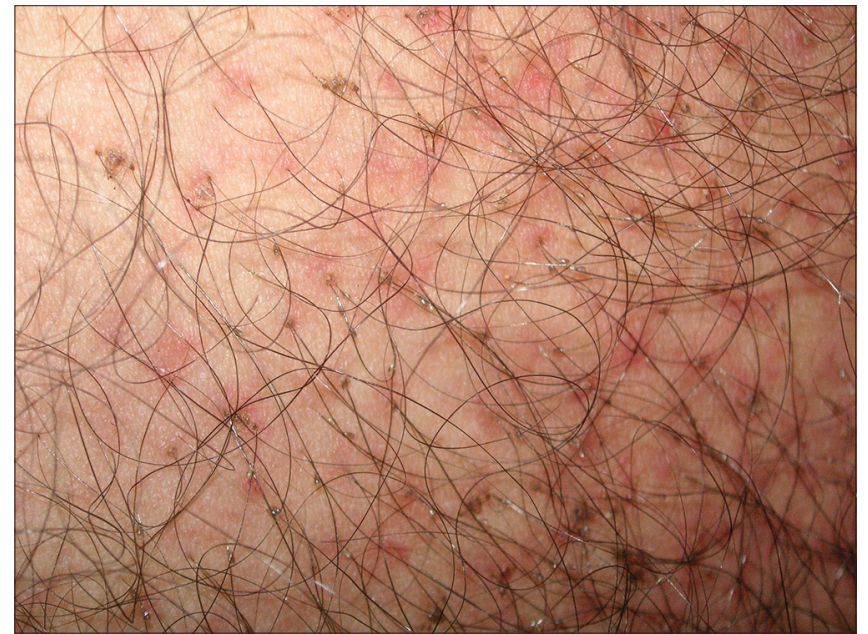

Figure 1: Multiple pigmented macules and overlying particles attached near the base of the pubic hairs.

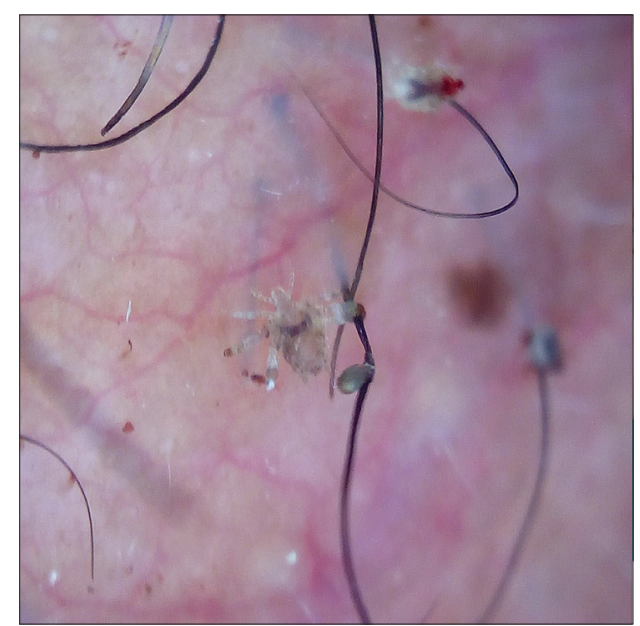

Figure 2: A clear visualization of pediculus pubis near the base of the pubic hairs by dermoscopy (DermLite DL4, 10x).

a sexually transmitted infection transmitted by direct contact $[1,2,5]$. Hence, screening such patients for other sexually transmitted infections is strongly recommended $[1,5]$. Genital pruritus accompanying pediculosis pubis may be complicated by bacterial

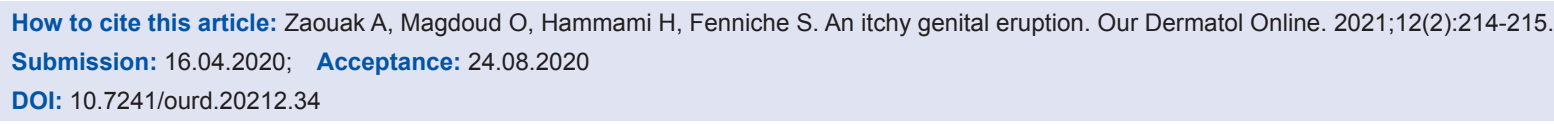


superinfection of excoriations [5]. Patients should be re-examined after one week especially if the symptoms persist and retreated if lice are discovered [1]. Sexual partners should be treated to prevent repeat transmission [6].

In summary, we strongly recommend dermoscopy as an accurate and rapid diagnostic tool for the diagnosis of pediculosis pubis.

\section{ACKNOWLEDGMENTS}

We would like to thank the patient.

\section{Consent}

The examination of the patient was conducted according to the principles of the Declaration of Helsinki.

The authors certify that they have obtained all appropriate patient consent forms, in which the patients gave their consent for images and other clinical information to be included in the journal. The

patients understand that their names and initials will not be published and due effort will be made to conceal their identity, but that anonymity cannot be guaranteed.

\section{REFERENCES}

1. Salavastru CM, Chosidow O, Janier M, Tiplica GS. European guideline for the management of pediculosis pubis. J Eur Acad Dermatol Venereol. 2017;31:1425-8.

2. Zhang M, Kaffenberger B. Pigmented pruritic macules in the genital area. Cutis. 2018;102:E21-2.

3. Ko CJ, Elston DM. Pediculosis. J Am Acad Dermatol. 2004;50:1-12; quiz 13-14.

4. Li L, Liu X, Xu L, Lu Y. Dermoscopy of pediculosis pubis. JAAD Case Rep. 2018;4:168-9.

5. Coates SJ, Thomas C, Chosidow O, Engelman D, Chang AY. Ectoparasites: pediculosis and tungiasis. J Am Acad Dermatol. 2020;82:551-69.

6. Workowski KA, Bolan GA. Sexually transmitted diseases treatment guidelines, 2015. MMWR Recomm Rep. 2015;64:1-137.

Copyright by Anissa Zaouak, et al. This is an open-access article distributed under the terms of the Creative Commons Attribution License, which permits unrestricted use, distribution, and reproduction in any medium, provided the original author and source are credited.

Source of Support: Nil, Conflict of Interest: None declared. 